\section{(A) OPEN ACCESS}

\title{
Safety profiles of anti-VEGF drugs: bevacizumab, ranibizumab, aflibercept and ziv-aflibercept on human retinal pigment epithelium cells in culture
}

\author{
Deepika Malik, ${ }^{1}$ Mohamed Tarek, ${ }^{1,2}$ Javier Caceres del Carpio, ${ }^{1}$ Claudio Ramirez, ${ }^{1}$ \\ David Boyer, ${ }^{3}$ M Cristina Kenney, ${ }^{1}$ Baruch D Kuppermann ${ }^{1}$
}

\begin{abstract}
${ }^{1}$ Department of
Ophthalmology, Gavin Herbert

Eye Institute, University of

California, Irvine, California,

USA

${ }^{2}$ Department of

Ophthalmology, El-Minya

University, El-Minya, Egypt

${ }^{3}$ Retina-vitreous Associates

Medical Group, Los Angeles,

California, USA
\end{abstract}

\section{Correspondence to}

Dr Baruch D Kuppermann, Department of Ophthalmology,

Gavin Herbert Eye Institute,

UC, Irvine, 850 Health

Sciences Road, Irvine,

CA 92697, USA;

bdkupper@uci.edu

Received 25 March 2014 Accepted 30 March 2014

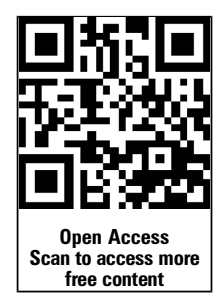

CrossMark

To cite: Malik D, Tarek M,
Caceres del Carpio J, et al.
Br J Ophthalmol 2014;98:
i11-i16.

\section{ABSTRACT}

Purpose To compare the safety profiles of antivascular endothelial growth factor (VEGF) drugs ranibizumab, bevacizumab, aflibercept and ziv-aflibercept on retinal pigment epithelium cells in culture.

Methods Human retinal pigment epithelium cells (ARPE-19) were exposed for $24 \mathrm{~h}$ to four anti-VEGF drugs at $1 / 2 \times, 1 \times, 2 \times$ and $10 x$ clinical concentrations. Cell viability and mitochondrial membrane potential assay were performed to evaluate early apoptotic changes and rate of overall cell death.

Results Cell viability decreased at $10 \times$ concentrations in bevacizumab $(82.38 \%, p=0.0001)$, aflibercept $(82.68 \%, p=0.0002)$ and ziv-aflibercept $(77.25 \%$, $p<0.0001)$, but not at lower concentrations. However, no changes were seen in cell viability in ranibizumabtreated cells at all concentrations including 10x. Mitochondrial membrane potential was slightly decreased in $10 \times$ ranibizumab-treated cells $(89.61 \%$, $\mathrm{p}=0.0006$ ) and $2 \times$ and $10 \times$ aflibercept-treated cells $(88.76 \%, 81.46 \% ; p<0.01$, respectively). A larger reduction in mitochondrial membrane potential was seen at $1 \times, 2 x$ and $10 x$ concentrations of bevacizumab $(86.53 \%, 74.38 \%, 66.67 \% ; p<0.01)$ and ziv-aflibercept $(73.50 \%, 64.83 \%$ and $49.65 \% p<0.01)$ suggestive of early apoptosis at lower doses, including the clinical doses.

Conclusions At clinical doses, neither ranibizumab nor aflibercept produced evidence of mitochondrial toxicity or cell death. However, bevacizumab and ziv-aflibercept showed mild mitochondrial toxicity at clinically relevant doses.

\section{INTRODUCTION}

Abnormal neovascularisation and vascular permeability is the underlying pathology in exudative age-related macular degeneration (AMD) leading to blindness in $1.5 \%$ of the US population, including $11.8 \%$ of adults that are greater than 80 years of age. ${ }^{1-4}$ Angiogenesis is controlled by positive regulators: vascular endothelial growth factor A (VEGF-A), transforming growth factor $\alpha$ and $\beta$, fibroblast growth factor, hepatocyte growth factor, connective tissue growth factor and interleukins; and negative regulators: pigment epithelium-derived factor (PEDF), thrombostatin, angiostatin and endostatins. ${ }^{5}$ VEGF-A supports endothelial cell proliferation and survival by degrading the basement membrane and stimulating cell migration. Another important function that is mediated by VEGF-A is vascular permeability, which is significant in retinal diseases, such as AMD, retinal venous occlusions and diabetic macular oedema. ${ }^{6-12}$ VEGF-A is a critical pro-angiogenic factor secreted as numerous splice isoforms that together regulate the phenotype and efficacy of growing vascular networks. ${ }^{13}$ Placental growth factor (PIGF), one of VEGF family member, is involved in formation of collateral arterioles from pre-existing arterioles. ${ }^{14}$

The advent of anti-VEGF drugs has revolutionised the treatment of wet AMD. Ranibizumab and bevacizumab are humanised monoclonal antibodies that bind with high affinity to the VEGF-A isoforms (eg, $\mathrm{VEGF}_{110}, \mathrm{VEGF}_{121}$ and $\mathrm{VEGF}_{165}$ ), thereby preventing binding of VEGF-A to its receptors VEGFR-1 and VEGFR-2. Aflibercept and ziv-aflibercept are recombinant fusion proteins that act as soluble decoy receptors that bind VEGF and PlGF. Ranibizumab (Lucentis; Genentech, San Francisco, California, USA) is US Food Drug and Administration (US FDA) approved for the treatment of wet AMD, macular oedema associated with retinal vein occlusions and diabetic macular oedema. Aflibercept (Eylea; Regeneron, Tarrytown, New York, USA) is approved by FDA for treatment of wet AMD and macular oedema following central retinal vein occlusions. Recent Phase 3 VISTA-DME and VIVID-DME results support greater improvement in visual acuity in DME patients treated with aflibercept than laser photocoagulation. ${ }^{15}$ In 2004, Bevacizumab (Avastin; Genentech, San Francisco, California, USA) was approved by FDA for the treatment of metastatic colorectal carcinomas, renal carcinomas and glioblastoma multiforme of the brain. Since bevacizumab has inhibitory effects on VEGF and is one of the least expensive options, it is being used off-label for treatment of AMD, diabetic retinopathy, retinal venous occlusions and iris neovascularisation. Ziv-aflibercept (Zaltrap; Regeneron, Tarrytown, New York, USA) is an adaptive variant of aflibercept. Zaltrap was approved by FDA in August 2012, for the treatment of metastatic colorectal carcinoma that is resistant to or has progressed following an oxiplatin-containing regimen. Aflibercept is a preservative-free formulation. Ziv-aflibercept has lower $\mathrm{pH}$ and higher osmolality when compared with aflibercept. The effects of ziv-aflibercept on retinal cells are unknown.

The differences in molecular structure of these drugs may have variable effects on enzymatic activity and metabolic processes in retinal cells. In this in vitro, experimental study, we evaluated the safety profiles of four anti-VEGF drugs-ranibizumab, bevacizumab, aflibercept and ziv-aflibercept 
on human retinal pigment epithelial (RPE) cells. This experiment was designed to study three specific cell parameters of these four anti-VEGF drugs on RPE cells in culture in order to assess their relative safety profiles (1) to determine the overall cytotoxicity by assessing the cell viability after drug exposure; (2) to detect early mitochondrial damage by using sensitive in vitro tests that measure changes in the mitochondrial membrane potential indicating early apoptosis; (3) to detect changes in the osmolality of the culture media after adding the anti-VEGF drugs.

The significance of this study is that this human tissue culture system makes it possible to use very sensitive methods to identify subtle changes in human retinal cellular responses to drugs, which cannot be identified in the diseased retinas in vivo. This is important because presently there are multiple drugs available for treatment of neovascularisation and it is not clear which, if any, have unintended side effects on the retinal cells.

\section{METHODS}

\section{Cell culture}

ARPE-19 cells are a spontaneously arising RPE cell line derived in 1986 by Amy Aotaki-Keen from the normal eyes of a 19-year-old male who died in a motor vehicle accident from head trauma. The ARPE-19 cell line, established using the cuboidal basal cell layer cultured in specific culture media, expresses the RPE-specific markers cellular retinaldehyde binding protein and RPE-65.

Human RPE cells (ARPE-19 cells, ATCC, Manassas, Virginia, USA) were grown in 1:1 mixture (vol/vol) of Dulbecco's modified Eagle's and Ham's nutrient mixture F-12; (Invitrogen-Gibco, Carlsbad, California, USA), non-essential amino acids $10 \mathrm{mM}$, $0.37 \%$ sodium bicarbonate, $0.058 \%$ L-glutamine, $10 \%$ fetal bovine serum, and antibiotics (penicillin G $100 \mathrm{U} / \mathrm{mL}$, streptomycin sulfate $0.1 \mathrm{mg} / \mathrm{mL}$, gentamicin $10 \mu \mathrm{g} / \mathrm{mL}$, amphotericin-B $2.5 \mu \mathrm{g} / \mathrm{mL}$ ). Cells were incubated at standard conditions $-37^{\circ} \mathrm{C}$ in $5 \% \mathrm{CO}_{2}$ and $95 \%$ relative humidity.

\section{ARPE-19 cell treatment with anti-VEGF drugs}

ARPE-19 cells were treated with $1 / 2 \times, 1 \times, 2 \times$ and $10 \times$ concentrations of all four anti-VEGF drugs (ranibizumab, bevacizumab, aflibercept, ziv-aflibercept). The clinical dose was calculated by assuming that the amount of each drug clinically used in intravitreal injections distributes equally throughout the $4 \mathrm{~mL}$ human vitreous. The clinical dose for each drug, defined as ' $\times$ ', were as follows (table 1 ):

\section{Cell viability assay}

Cell viability is an evaluation of living or dead cells based on a total cell sample. ARPE-19 cells were plated on six-well plates for the cell viability assay. $5.0 \times 10^{5}$ cells in $2 \mathrm{~mL}$ of culture media per well were plated and incubated in standard

Table 1 Indicates ' $x$ ' concentration for individual antivascular endothelial growth factor (VEGF) drug

\begin{tabular}{lll}
\hline $\begin{array}{l}\text { Anti-VEGF } \\
\text { drug }\end{array}$ & $\begin{array}{l}\text { Clinical dose }(\times) / 4 \mathrm{~mL} \text { of } \\
\text { vitreous }(\mathbf{m g})\end{array}$ & $\begin{array}{l}\text { Volume per } 4 \mathrm{~mL} \text { of culture } \\
\text { media }(\mathbf{m L})\end{array}$ \\
\hline Ranibizumab & 0.5 & 0.05 \\
Bevacizumab & 1.25 & 0.05 \\
Aflibercept & 2 & 0.05 \\
Ziv-aflibercept & 2 & 0.08 \\
\hline
\end{tabular}

conditions for $24 \mathrm{~h}$. Then the culture media were replaced with fresh culture media containing defined doses (control-no drug, $1 / 2 \times, 1 \times, 2 \times$ and $10 \times$ ) of all four drugs. Cells were incubated for another $24 \mathrm{~h}$ and then trypsinised and centrifuged at $1000 \mathrm{rpm}$ for $5 \mathrm{~min}$. The cells were resuspended in $1 \mathrm{~mL}$ of culture medium and an automated trypan blue dye exclusion assay for cell viability was performed with ViCell XR cell viability analyser (Beckman Coulter, Fullerton, California, USA). All assays were performed in triplicate and repeated twice.

\section{Mitochondrial membrane potential $(\Delta \Psi \mathrm{m})$ assay}

ARPE-19 cells were plated $\left(1.0 \times 10^{5}\right.$ per well $)$ overnight in 24-well plates for $24 \mathrm{~h}$ and then incubated another $24 \mathrm{~h}$ in $1 \mathrm{~mL}$ of culture media containing predefined concentrations of all four drugs. Detection of mitochondrial membrane potential $(\Delta \Psi \mathrm{m})$ was performed using the JC-1 detection kit (Biotium, Hayward, California, USA) according to the manufacturer's directions. JC-1 (5, 5',6,6'-tetrachloro-1, $1^{\prime}, 3,3^{\prime}$-tetraethyl-benzimidazolyl-carbocyanine-iodide) is a cationic dye which accumulates in mitochondrial membranes of healthy cells, resulting in red fluorescence $(590$ $\mathrm{nm}$ ), while in apoptotic and necrotic cells, which have diminished mitochondrial membrane potential, JC-1 exists in the green fluorescent $(529 \mathrm{~nm})$ monomer form. Images are captured using a fluorescence image scanning unit (FMBIO III) instrument (Hitachi, Yokohama, Japan) and the ratios of red (live cells) and green (dead cells) fluorescence were calculated. All assays were performed in quadruples and repeated twice.

\section{Osmolality of media containing anti-VEGF drugs}

Osmolality is a measure of the osmolar concentration of solution and is proportional to the number of particles per kilogram of solvent. When a solute is dissolved in a pure solvent, certain properties of the solvent are changed such as, the freezing point is depressed, the boiling point is raised, the osmotic pressure is increased, and the vapour pressure is lowered. These are the so-called colligative or concentrative properties of the solvent which, within reasonable limits, change in direct proportion to the solute concentration. Osmolalities of the culture media containing anti-VEGF drugs were measured using Automated Fiske osmometer (Advanced Instruments, Norwood, Massachusetts, USA), which uses high-precision electronic thermometers to test the sample.

\section{Statistical analysis}

Data were subjected to statistical analysis by analysis of variance (ANOVA) using GraphPad Prism V.5.0 version statistics program (GraphPad Software, San Diego, California, USA). Control readings were normalised to $100 \%$ in each experiment, and percentage changes in cell viability or mitochondrial membrane potential for each drug were calculated. Data is presented as mean \pm SEM. $\mathrm{p}$ Values $<0.05$ were considered statistically significant.

\section{RESULTS}

All four drugs, ranibizumab, bevacizumab, aflibercept and ziv-aflibercept were assessed for cell viability and mitochondrial membrane potential on ARPE-19 cells in culture at doses ranging from $1 / 2 \times$ to $10 \times$ clinical dose.

\section{Effect on cell viability}

Ranibizumab was found to be safe at all doses of treatment. There was no statistically significant difference between control and all other doses tested from $1 / 2 \times$ to $10 \times$ clinical dose. Cell viability of cells treated with $10 \times$ dose of bevacizumab, aflibercept and ziv-aflibercept showed a statistically significant decrease 
to $82.38 \pm 1.5 \%(\mathrm{p}=0.0002), 82.62 \pm 1.7 \% \quad(\mathrm{p}=0.0001)$ and $77.25 \pm 2.1 \%(\mathrm{p}<0.0001)$, respectively. There were no statistically significant differences observed at $1 / 2 \times, 1 \times$ and $2 \times$ within each other or from control/untreated cells for bevacizumab, aflibercept and ziv-aflibercept (figure 1A-D).

\section{Effect on mitochondrial membrane potential $(\Delta \Psi \mathrm{m})$}

The readings of control wells were averaged and normalised to $100 \%$, and the percentage decrease in mitochondrial membrane potential for each well was then calculated (figure 2).

Ranibizumab (figure 2A): The mitochondrial membrane potential was $89.61 \pm 1.7 \%(p=0.0006)$ for the $10 \times$ clinical dose which was significantly reduced when compared with control wells. There were no statistically significant differences observed at the other clinical doses when compared with controls $(100 \pm 1.6 \%)$. The values were $98.73 \pm 2.78 \%, 96.77$ $\pm 2.783 \%$ and $94.68 \pm 2.54 \%$ for $1 / 2 \times, 1 \times$ and $2 \times$ clinical doses for ranibizumab, respectively $(\mathrm{p}<0.05)$.

Bevacizumab (figure 2B): The mitochondrial membrane potential was significantly reduced in bevacizumab-treated wells at the $10 \times$ and $2 \times$ and $1 \times$ clinical doses compared with controls $(99.96 \pm 2.8 \%)$. The ratios of the red/green fluorescence were $66.67 \pm 2.5 \% \quad(\mathrm{p}<0.0001)$ for $10 \times, \quad 74.38 \pm 1.3 \%$ $(\mathrm{p}<0.0001)$ for $2 \times$, and $86.53 \pm 1.8 \%(\mathrm{p}=0.0014)$ for $1 \times$ concentration.

Aflibercept (figure 2C): There were statistically significant decreases in mitochondrial membrane potential observed at $10 \times$ and $2 \times$ clinical doses in cells treated with aflibercept. The values were $81.46 \pm 1.97 \%(p<0.0001)$ at $10 \times$ and 88.76 $\pm 1.18 \%(\mathrm{p}=0.0002)$ at $2 \times$. However, no significant differences were seen at $1 \times(94.76 \pm 2.9 \%)$ and $1 / 2 \times(96.22 \pm 2.0 \%)$ clinical doses when compared with controls $(100 \pm 1.9 \%)$.

Ziv-aflibercept (figure 2D): The mitochondrial membrane potential was significantly reduced at $10 \times, 2 \times$, and $1 \times$ doses as follows: $\Delta \Psi \mathrm{m}$ was $49.65 \pm 4.22 \%(\mathrm{p}=0.0002)$ at $10 \times, 64.83$ $\pm 2.7 \%(\mathrm{p}<0.0001)$ at $2 \times$ and $73.50 \pm 2.93 \%(\mathrm{p}<0.0001) 1 \times$ doses of ziv-aflibercept, which were significantly reduced when compared with controls $(100 \pm 4.38 \%)$. The ratio was 91.57 $\pm 2.54 \%$ at $1 / 2 \times$ dose which was statistically insignificant.

\section{Effect on osmolality}

Table 2 represents the osmolality of culture media at $10 \times$ drug concentrations. These results show an increased osmolality of sample containing ziv-aflibercept ie $418 \mathrm{mOsm} / \mathrm{kg}$ when compared with ranibizumab (322 $\mathrm{mOsm} / \mathrm{kg})$, bevacizumab (342 mosm $/ \mathrm{kg})$, aflibercept $(317 \mathrm{mOsm} / \mathrm{kg}$ ) and control sample $(324 \mathrm{mOsm} / \mathrm{kg})$. Based on these findings, we tested the osmolality of ziv-aflibercept in ARPE-19 culture media at all tested concentrations. At $1 / 2 \times, 1 \times$ and $2 \times$ concentration of ziv-aflibercept, the osmolality was recorded as 324,330 and $342 \mathrm{mosm} / \mathrm{kg}$, respectively, which is not significantly different as compared with controls $(328 \mathrm{mOsm} / \mathrm{kg})$.

\section{DISCUSSION}

This invitro study compares the effect of different concentrations of four commercially available anti-VEGF drugs-ranibizumab, bevacizumab, aflibercept and ziv-aflibercept on human retinal pigment epithelium cells.
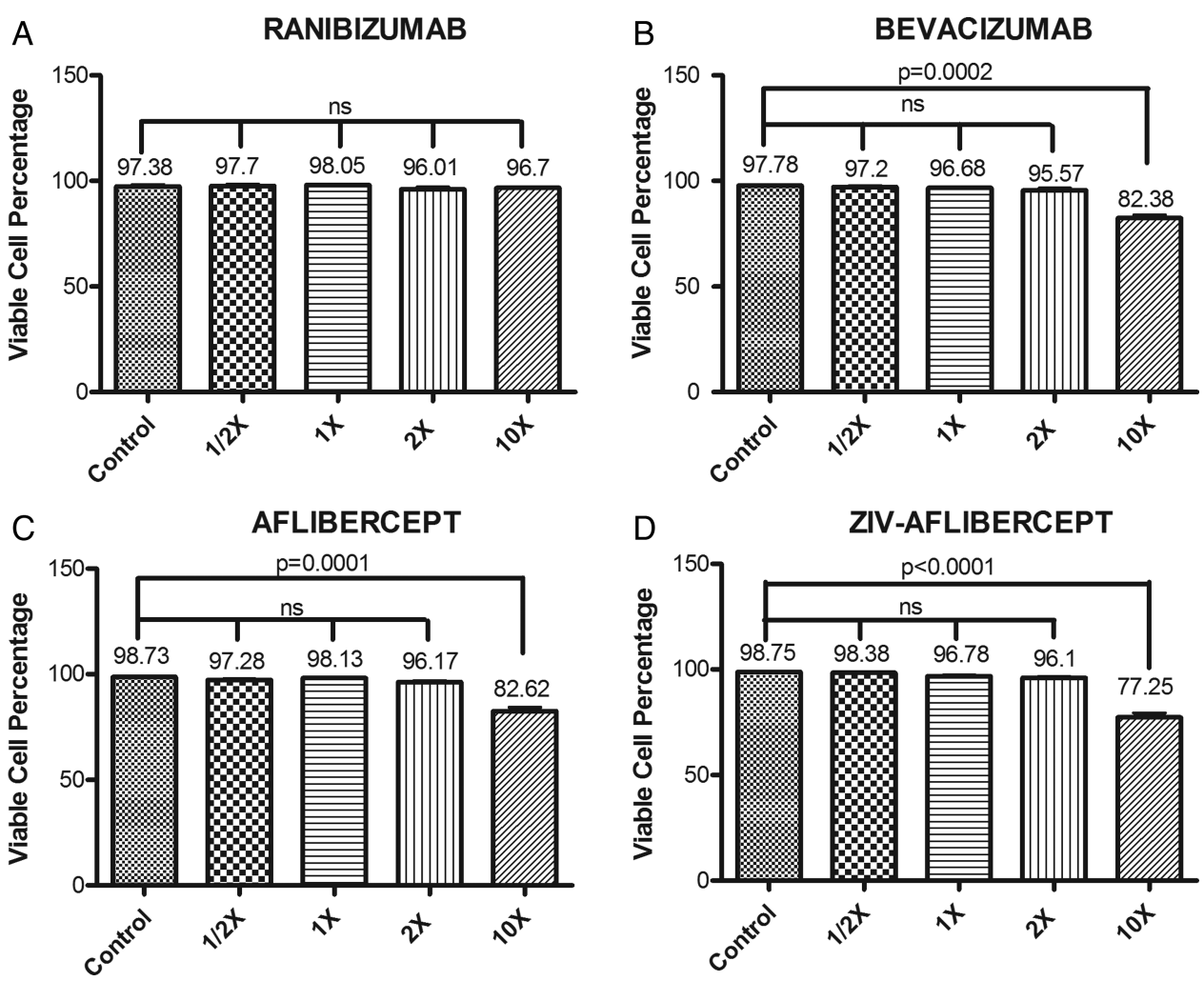

Figure 1 Cell viability assay. (A) No significant decrease in \% cell viability was seen in $1 / 2 \times, 1 \times, 2 \times, 10 \times$ ranibizumab-treated ARPE-19 cells, $p>0.05$. (B) Cell viability decreased to $82 \%$ in $10 \times$ bevacizumab-treated cells when compared with controls ( $p=0.0002$ ). No statistically significant change in cell viability was observed on treatment with either $1 / 2 \times, 1 \times$, or $2 x$ concentration of bevacizumab. (C) A statistically significant decrease in cell viability $(83 \%)$ was seen in $10 x$ aflibercept-treated cells $(p=0.0001)$. There was no significant change in $1 / 2 \times, 1 \times$ and $2 \times$ concentrations when compared with controls, $p>0.05$. (D) Ziv-aflibercept-treated ARPE-19 cells showed a $77 \%$ reduction of cell viability at 10 concentration, $p<0.0001$. No statistically significant change was observed at all other concentrations. 
A

RANIBIZUMAB

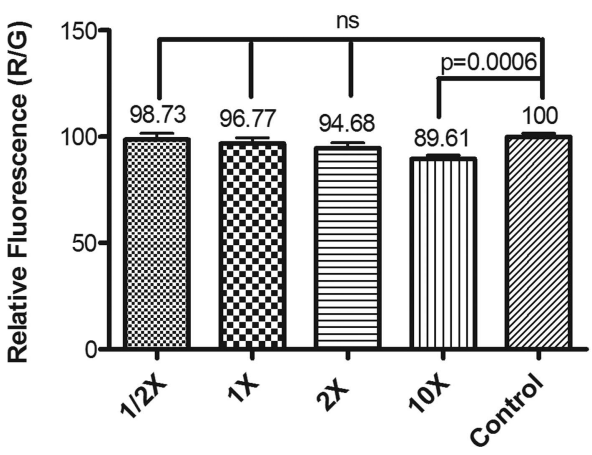

C

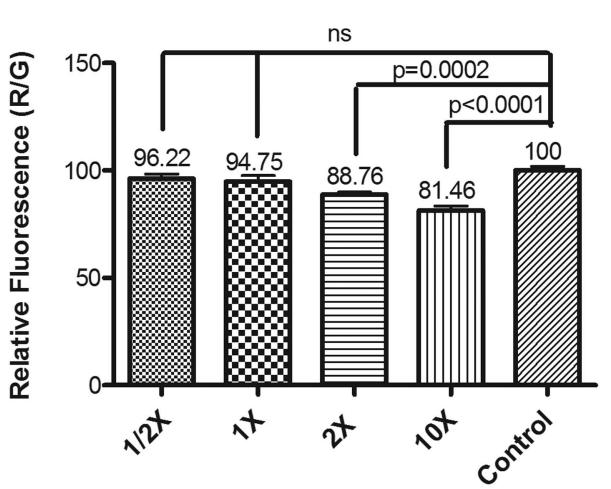

B
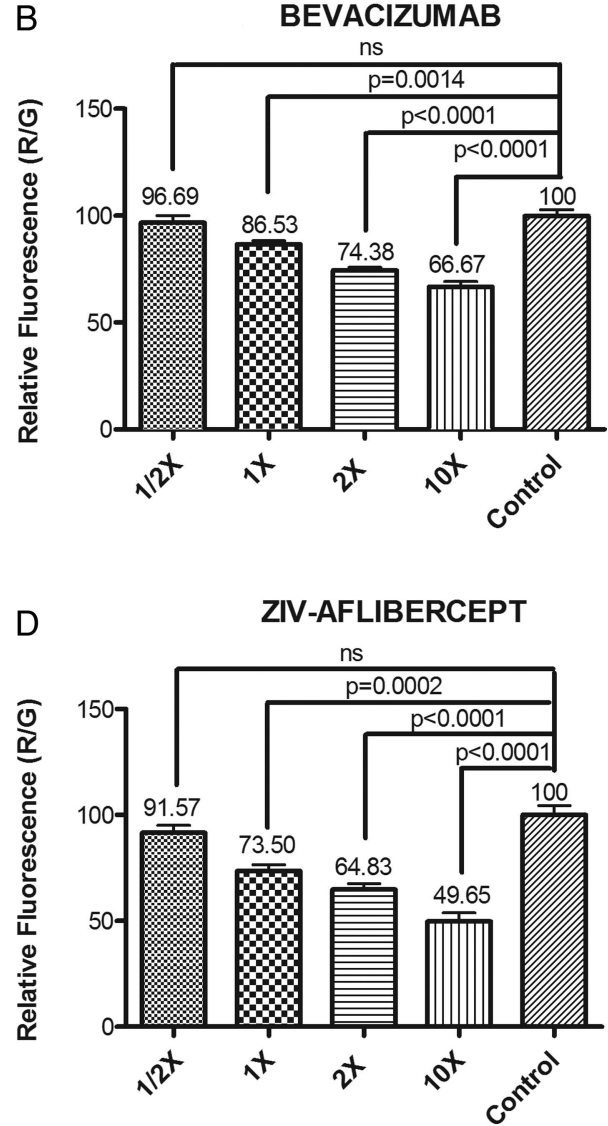

Figure 2 Mitochondrial membrane potential $(\Delta \Psi \mathrm{m})$ assay: (A) There was a statistically significant decrease in mitochondrial membrane potential that was observed at $10 x$ concentration of ranibizumab, $p<0.05$. (B) The live/dead cell ratio was significantly lower in $10 x, 2 x$ and $1 x$ bevacizumab-treated ARPE-19 cells compared with untreated controls $(p<0.0001, p<0.0001$ and $p=0.0014$, respectively). There was a statistically significant decrease in the red/green ratio in the $10 \times$ bevacizumab-treated cells compared with $10 \times$ ranibizumab-treated cells $(p<0.001)$. No statistically significant changes in $\Delta \Psi \mathrm{m}$ were seen on $1 / 2 \times$ bevacizumab and $1 / 2 x, 1 \times, 2 \times$ and $10 x$ ranibizumab-treated cells. (C) A statistically significant decrease in live/dead cell ratio was seen in $10 x$ and $2 \times$ aflibercept-treated cells, $p<0.0001, p=0.0002$. (D) All concentrations of ziv-aflibercept except $1 / 2 \times$ showed significant decrease in mitochondrial membrane potential revealing marked mitochondrial toxicity. The mitochondrial membrane potential at $1 \times$ concentration of ziv-aflibercept is significantly decreased when compared with aflibercept, bevacizumab and ranibizumab $(p<0.001)$.

Our previous data presented by Luthra et al comparing the cell damage response of bevacizumab and ranibizumab, demonstrated no statistically significant differences in cell viability at $1 \times, 2 \times$ and $5 \times$ concentrations in human RPE cell line (ARPE-19) cultures and rat neurosensory retina cell line (R28) cultures. However, decreased mitochondrial membrane potentials were observed at $2 \times$ and $5 \times$ doses of bevacizumab. ${ }^{16} 17$

In this study, we did not observe any effect on the cell viability of human RPE cells at $1 / 2 \times, 1 \times, 2 \times$ doses of all four anti-VEGF drugs studied. However, at $10 \times$ doses, all other

Table 2 Effect of antivascular endothelial growth factor drugs on osmolality of ARPE-19 culture media at $10 \times$ concentrations

\begin{tabular}{ll}
\hline & Osmolality (m0sm/kg) \\
\hline Control & 324 \\
Ranibizumab & 322 \\
Bevacizumab & 342 \\
Aflibercept & 317 \\
Ziv-aflibercept & 418 \\
\hline
\end{tabular}

drugs except ranibizumab demonstrated a decreased cell viability/survival. A decreased mitochondrial membrane potential indicates early apoptosis. After $24 \mathrm{~h}$ of treatment with ranibizumab, RPE cells demonstrated slight decrease in mitochondrial membrane potential at $10 \times$ dose when compared with untreated cells. Aflibercept was safe at $1 / 2 \times, 1 \times$ and $2 \times$ when tested for cell viability, but mitochondrial damage was observed at $2 \times$ and $10 \times$ doses. Bevaizumab-treated ARPE-19 cells showed decreased mitochondrial membrane potential at $1 \times, 2 \times$ and $10 \times$ concentrations. All tested doses except $1 / 2 \times$ were found to be detrimental for overall health of mitochondria in ziv-aflibercept-treated cells.

Deissler et $a l,{ }^{18}$ reported more efficient inhibition of VEGF-induced proliferation by ranibizumab than bevacizumab in immortalised bovine retinal endothelial cells. The VEGF-inhibitory abilities were completely lost after storage of bevacizumab for 4 weeks in $4^{\circ} \mathrm{C}$. Additionally, they reported accumulation of bevacizumab in cytoskeleton and membranes and organelles of bovine RPE cells until day 6 of incubation. ${ }^{18}$ Klettner et al, ${ }^{19}$ demonstrated accumulation and presence of bevacizumab, but not ranibizumab, in porcine RPE cells by flow cytometry intracellularly and extracellularly, even after 7 days of drug exposure at clinically relevant doses. However, they found 
some levels of ranibizumab after $1 \mathrm{~h}$ of incubation in RPE cells by confocal laser microscopy which was undetectable by flow cytometry. No ranibizumab was detected intracellularly and extracellularly at day 1 and day 7 of incubation. ${ }^{19}$ The accumulation of bevacizumab in retinal cells after hours and days of treatment may be responsible for the loss of mitochondrial membrane potential at $1 \times, 2 \times$ and $10 \times$ doses and increased cell death at $10 \times$ doses as observed in our study on RPE cells in culture.

Yourey et $a l,{ }^{20}$ have demonstrated the role of VEGF in growth and development of photoreceptor cells. A recent report from Kurihara et $a l^{21}$ reported blocking VEGF-A in adult mouse RPE cells rapidly led to vision loss and ablation of the choriocapillaris. This data supports our in vitro experimental findings of increased cell death and mitochondrial damage at higher concentrations of anti-VEGF agents. Manousaridis et al ${ }^{22}$ have also recently reported a possible role of anti-VEGF therapy in worsening of macular ischaemia in long-term diabetic macular oedema.

Schnichels et al, reported the effects of aflibercept $(0.125,0.5$, $2 \mathrm{mg}$ ) after 1, 24, 48 and $72 \mathrm{~h}$ on ARPE-19 cells. At all time points, aflibercept did not cause changes in cell morphology, induce apoptosis or cause permanent decrease in cell viability, cell density or proliferation in any cell line or concentration investigated. ${ }^{23}$ Recently, Ammar et al, ${ }^{24}$ reported no detrimental effect of aflibercept on human trabecular meshwork cells and ARPE-19 cells at $1 \mathrm{mg} / \mathrm{mL}$ concentration. These findings are consistent with our results, which also demonstrate no decrease in cell viability compared with controls at $2 \times$ concentration tested. We found a decrease in mitochondrial membrane potential at $2 \times$ and $10 \times$ clinical doses. Although the decrease in mitochondrial membrane potential is statistically significant at $2 \times$ concentration $(88.76 \%)$ of aflibercept, the cell viability at $1 \times$ and $2 \times$ doses is $98.3 \%$ vs $96.7 \%$ which indicates a mild toxicity at $2 \times$ clinical dose in terms of mitochondrial damage but not overall cell death.

Our study demonstrates ranibizumab to have the broadest safety profile of all studied anti-VEGF drugs tested for the overall health of retinal pigment epithelium cells. Ranibizumab, is derived from the same parent mouse antibody as bevacizumab, but differs from the corresponding part in bevacizumab by six amino acids, absence of Fc region, and has a smaller molecular size $(48.39 \mathrm{kDa}$ as opposed to $149 \mathrm{kDa}$ of bevacizumab). Removal of Fc region in ranibizumab has resulted in reduced potential to initiate immune-mediated inflammation, shorter half-life and rapid systemic clearance, hence minimising the systemic exposure. The 2 year (multicentre) results of the Comparison of Age-related macular degeneration Treatment Trials published in 2012, have indicated that at 2 years, bevacizumab is equivalent to ranibizumab in the treatment of wet AMD when using similar dosing regimens, in terms of visual acuity gain and safety profiles. ${ }^{25}$ However, in our study, slightly increased mitochondrial damage was observed in bevacizumabtreated retinal cells in vitro at $1 \times$ clinical dose. Our findings differ from the clinical data due to either presence of multiple protective factors that influence the overall effect on retinal cells in vivo or possibly the slight decrease in mitochondrial membrane potential, as observed in our study, may be correlated to a subclinical damage which is not appreciated while assessing visual acuity in bevacizumab-treated subjects. Since the mitochondrial membrane potential assay used here uses JC1 dye which is highly sensitive, it is able to detect even very early signs of apoptosis.

The binding affinity of aflibercept to VEGF-A is substantially greater than ranibizumab, so that aflibercept can be potentially used for an extended dosing interval compared with ranibizumab. VIEW 1 and VIEW 2 studies have reported favourable safety profiles for intravitreal use of aflibercept and ranibizumab for the treatment of wet AMD. ${ }^{26}$ In our study, aflibercept produces less mitochondrial damage when compared with bevacizumab, but exhibits a less robust safety profile than ranibizumab which may be correlated to the higher binding affinity of aflibercept than ranibizumab.

Ziv-aflibercept is an adaptive variant of aflibercept, having similar molecular structure and mechanism of action. It has been recently approved by FDA for treatment of colorectal cancers. Since ziv-aflibercept and aflibercept have similar molecular structure, we decided to test ziv-aflibercept at similar concentrations as aflibercept. Our study demonstrated increased mitochondrial toxicity in vitro in ARPE- 19 cells at $1 \times, 2 \times$ and $10 \times$ concentrations, which may be because ziv-aflibercept has lower $\mathrm{pH}$ and higher osmolality when compared with aflibercept. Aflibercept is a preservative-free formulation. These factors may influence the increased observed cytotoxicity of ziv-aflibercept on retinal cells in vitro. However, further studies are underway to better understand the potential mechanisms by which ziv-aflibercept may induce its increased cytotoxicity relative to the other anti-VEGF drugs tested.

\section{CONCLUSION}

Our in vitro study on immortalised human RPE cells demonstrated that ranibizumab and aflibercept exhibit no retinal cytotoxicity at standard clinical doses. However, ziv-aflibercept and bevacizumab revealed mitochondrial toxicity at clinically relevant concentrations.

Contributors DM, BDK, MCK, MT, JCdC, CR and DB contributed to the conception or design of the work, and the acquisition, analysis or interpretation of data; drafting the work or revising it critically for important intellectual content; and final approval of the version published. All authors ensured agreement to be accountable for all aspects of the work in ensuring that questions related to the accuracy or integrity of any part of the work are appropriately investigated and resolved.

Funding Supported by the Discovery Eye Foundation, Beckman Macular Research Initiative, Polly and Michael Smith Foundation, Max Factor Family Foundation, Skirball Foundation, Lincy Foundation The Henry L Guenther Foundation, The Iris and B Gerald Cantor Foundation, an unrestricted grant from Research to prevent Blindness, and Pan-American Association of Ophthalmology Foundation (David \& Julianna Pyott Pan-American-Retina Research Fellowship).

\section{Competing interests None.}

Provenance and peer review Not commissioned; externally peer reviewed.

Open Access This is an Open Access article distributed in accordance with the Creative Commons Attribution Non Commercial (CC BY-NC 3.0) license, which permits others to distribute, remix, adapt, build upon this work non-commercially, and license their derivative works on different terms, provided the original work is properly cited and the use is non-commercial. See: http://creativecommons.org/ licenses/by-nc/3.0/

\section{REFERENCES}

1 Friedman DS, O'Colmain BJ, Munoz B, et al. Prevalance of age-related macular degeneration in the United States. Arch Ophthalmol 2004;122:564-72.

2 Garner A. Vascular diseases. In: Garner A, Klintworth GK, eds. Pathobiology of ocular disease. 2nd edn. New York: Marcel Dekker, 1994:1625-710.

3 Adamis AP, Shima DT. The role of vascular endothelial growth factor in ocular health and disease. Retina 2005;25:111-18.

4 Krzystolik MG, Afshari MA, Adamis AP, et al. Prevention of experimental choroidal neovascularization with intravitreal anti-vascular endothelial growth factor antibody fragment. Arch Ophthalmol 2002;120:338-46.

5 Witmer AN, Vrensen GF, Van Noorden CJ, et al. Vascular endothelial growth factors and angiogenesis in eye disease. Prog Retin Eye Res 2003;22:1-29.

6 Hera R, Keramidas M, Peoc'h M, et al. Expression of VEGF and angiopoietins in subfoveal membranes from patients with age-related macular degeneration. Am J Ophthalmol 2005;139:589-96.

7 Dvorak HF, Brown LF, Detmar M, et al. Vascular permeability factor/vascular endothelial growth factor, microvascular hyperpermeability, and angiogenesis. Am J Pathol 1995:146:1029-39. 
8 Adamis AP, Miller JW, Bernal M-T, et al. Increased vascular endothelial growth factor levels in the vitreous of eyes with proliferative diabetic retinopathy. Am $J$ Ophthalmol 1994:118:445-50.

9 Abouammoh MA. Ranibizumab injection for diabetic macular edema: metaanalysis of systemic safety and systematic review. Can J Ophthalmol 2013;48: 317-23.

10 Iturralde D, Spaide RF, Meyerle CB, et al. Intravitreal bevacizumab (Avastin) treatment of macular edema in central retinal vein occlusion: a short-term study. Retina 2006;26:279-84.

11 Rouvas A, Petrou P, Vergados I, et al. Intravitreal Ranibizumab for the treatment of central retinal vein occlusion: a prospective study. Graefes Arch Clin Exp Ophthalmol 2009:247:1609-16.

12 Singer MA, Cohen SR, Groth SL, et al. Comparing bevacizumab and ranibizumab for initial reduction of macular thickness in patients with retina vein occlusions. Clin Ophthalmol 2013;7:1377-83.

13 Cébe Suarez S, Pieren M, Cariolato L, et al. A VEGF-A splice variant defective for heparan sulfate and neuropilin-1 binding shows attenuated signaling through VEGFR-2. Cell Mol Life Sci 2006:63:2067-77.

14 Zheng Y, Gu Q, Xu X. Inhibition of ocular neovascularization by a novel peptide derived from human placenta growth factor-1. Acta Ophthalmol 2012; 90:e512-23.

$15 \mathrm{http}: / /$ investor.regeneron.com/releasedetail.cfm?ReleaselD $=782911$

16 Luthra S, Narayanan R, Marques LE, et al. Evaluation of in vitro effects of bevacizumab (Avastin) on retinal pigment epithelial, neurosensory retinal, and microvascular endothelial cells. Retina 2006;26:512-18.
17 Malecaze F, Clamens S, Simorre-Pinatel V, et al. Detection of vascular endothelial growth factor messenger RNA and vascular endothelial growth factor-like activity in proliferative diabetic retinopathy. Arch Ophthalmol 1994;112:1476-82.

18 Deissler HL, Deissler H, Lang GE. Actions of bevacizumab and ranibizumab on microvascular retinal endothelial cells: similarities and differences. $\mathrm{Br} J$ Ophthalmol 2012;96:1023-8

19 Klettner AK, Kruse ML, Meyer T, et al. Different properties of VEGF-antagonists: Bevacizumab but not Ranibizumab accumulates in RPE cells. Graafes Arch Clin Exp Ophthalmol 2009;247:1601-8.

20 Yourey PA, Gohari S, Su JL, et al. Vascular endothelial cell growth factors promote the in vitro development of rat photoreceptor cells. J Neurosci 2000;20:6781-8.

21 Kurihara T, Westenskow PD, Bravo $S$, et al. Targeted deletion of Vegfa in adult mice induces vision loss. J Clin Invest 2012;122:4213-421.

22 Manousaridis K, Talks K. Macular ischaemia: a contraindication for anti-VEGF treatment in retinal vascular disease? Br J Ophthalmol 2012;96:179-84.

23 Schnichels S, Hagemann U, Januschowski K, et al. Comparative toxicity and proliferation testing of aflibercept, bevacizumab and ranibizumab on different ocular cells. Br J Ophthalmol 2013;97:917-23.

24 Ammar DA, Mandava N, Kahook MY. The effects of aflibercept on the viability and metabolism of ocular cells in vitro. Retina 2013;33:1056-61.

25 Martin DF, Maguire MG, Fine SL, et al. Ranibizumab and bevacizumab for treatment of neovascular age-related macular degeneration: two year results. Ophthalmology 2012;119:1388-98.

26 Heier JS, Brown DM, Chong V, et al. Intravitreal aflibercept (VEGF trap-eye) in wet age-related macular degeneration. Ophthalmology 2012;119:2537-48. 